\title{
PHYSICAL STUDY OF PLANETS AND SATELLITES
}

\section{(ETUDE PHYSIQUE DES PLANETES ET DES SATELLITES)}

\section{Report of Meeting, 10 Auqust 1988}

\section{PRESIDENT : A. Brahic}

At the 20th General Assembly of the IAU, Commission 16 held its business meeting, which opened at 9:00 a.m. on 10 August 1988, under the chairmanship of the incoming President, Dr. A. Brahic (France).

Oral minutes of the previous Business Meeting of Commission 16 were presented by Dr. D. Morrison (USA), who had been present at the meeting in India and had at that time been elected 2nd Vice President. Dr. Morrison noted that the President, Dr. G. Hunt (UK) had not been active in Commission business during his term, and that the organization of a session on planets at the 20th General Assembly had been largely due to the efforts of Dr. Brahic, to whom the commission members were grateful. Dr. Morrison also noted that attendance at the India commission meeting was very low (only about 5-6 people).

Dr. Morrison noted that at the India meeting, President V. G. Tejfel (USSR) had proposed the compilation of a volume of basic data on solar system bodies. Since that time there has been no information on progress on this volume, but after some general discussion, it was noted that commission 16 endorses Dr. Tejfel's proposed project.

Dr. Morrison noted that an informal meeting of several Commission 16 members had been recently held during the COSPAR meeting in Helsinki in July, at which time a proposed slate of new officers was drawn up with the concurrence of all those in attendance.

Dr. Brahic made a brief report on his activities on behalf of the commission.

Dr. Harold Masursky (USA) reported on the activities of the committee on nomenclature of planetary bodies. After some discussion, it was reaffirmed that the committee should retain its status as a committee rather than seek status as a comrnission of the IAU.

On the question of new officers, it was noted that the IAU General Secretary Dr. Swings had in earlier action rejected the slate of officers proposed following an informal business session of several Commission members at the COSPAR in Helsinki in July, 1988. The slate agreed upon in Helsinki was:
A. Brahic (France)
D. Morrison (USA)
D. P. Cruikshank (USA)
President
lst Vice President
2nd Vice President

The grounds for the rejection were the perceived large number of US scientists on the slate. Considerable discussion followed, after which it was decided by Dr. Brahic that the following revised slate should be presented:
A. Brahic (France)
D. Morrison (USA)
M. Ya. Marov (USSR)
President
lst Vice President
2nd Vice President

Dr. Brahic noted his plan to make a protest to the IAU Executive Committee on this matter, and to seek clarification on the question of whether the Commission 16 can really elect its own officers, or is the commission controlled by the IAU Executive Committee.

The Organizing Committee of Commission 16 was then discussed. The following individuals were nominated and approved by those in attendance: 


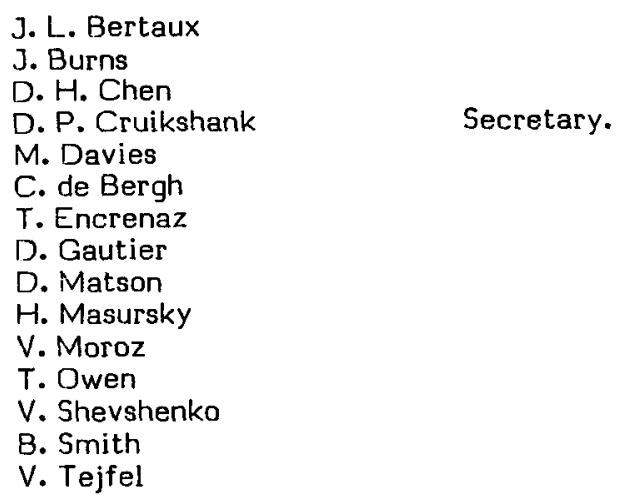

On the question of new and continuing members of Commission $16 \mathrm{Dr}$. Brahic noted that a large number (about 40-50) individuals had been proposed in earlier correspondence, though not all of those individuals were members of the IAU. Dr. Brahic noted that he would write to all of the proposed new members of Commission 16 to ascertain their interest in joining the Commission, and then would take steps to see that they are added to the membership list if interested.

Future meetings seeking sponsorship of endorsement by Comm. 16 include the following:

1. A meeting on Bioastronomy, SETI, and organic matter anywhere in the universe, to be held in France in 1990.

2. A conference on planetary astronomy to be held in the People's Republic of China in June 1989.

3. A meeting about Neptune to result in a book in the University of Arizona Press series on planets, to be held in Paris about two years after the Voyager Neptune encounter (which occurs in August 1989).

4. A meeting in October or November of 1989 to be held in France to discuss early results from the USSR's Phobos Mission to Mars.

Commission 16 endorses these Meetings.

D. Cruikshank (USA) noted that there is growing interest in a meeting on planets in the USSR which could be heavily attended by US scientists to discuss early results of the Phobos mission and the results of the Voyager Neptune encounter. The meeting is being proposed for late 1990. No endorsement was sought or given by the commission.

It was noted that at the scientific sessions of Commission 16 held on the previous day (9 August), attendance was exceptionally large (120-150 people). This large attendance was attributed to the high quality of the program plus the fact that Dr. Brahic had undertaken at his own initiative (and doing all the work himself) to print announcements of the session and distribute one to each member of the IAU in attendance at this General Assembly. All those present at this Business Meeting murmured their approval of Dr. Brahic's action.

In discussions of possible special topics for Commission 16 scientific sessions at the Argentinian General Assembly, T. C. Owen (USA) suggested that inner planets may be suitable, with special reports on the expected Magellan mission results. The results of Hubble Space Telescope observations of planetary bodies could also be reported. W. Irvine (USA) suggested that astrochemistry and the study of carbonaceous material would be suitable topics. 
The future activities of Commission 16 were discussed, and the following items were noted, with Dr. Brahic leading the discussions:

1. An update of the list of members is needed, and new members who wish to join should be added.

2. There is a need to assess the state of planetary astronomy worldwide, and Dr. Brahic suggested that this information could be gleaned from a widely circulated letter of inquiry to planetary astronomers.

3. Dr. Brahic proposes to publish and circulate a newsletter of Commission 16 activities and interests. He seeks input to that newsletter, the first issue of which he hopes to publish in about six months.

4. Acting on a suggestion by Dr. C. Keay that Commission 16 appoint some members to his working party (organized in Commission 22 - meteors and interplanetary dust) which seeks to frame recommendations on the composition and terms of reference of a highlevel panel on interplanetary pollution, Commission 16 shelved the matter until a later date.

5. Dr. R. West (USA) proposed that a working group on time-variable phenomena in the Jovian System be formed to act as a liaison with the International Jupiter Watch. Dr. West proposed the following text of a resolution:

"Commission 16 proposes the formation of a special working group on Time-Variable Phenomena in the Jovian Systern to coordinate ground-based observations of variable phenomena on the surfaces of Jovian satellites, the Io atmosphere and plasma Torus, and the Jovian magnetosphere and atmosphere. This working group will form liaisons with the International Jupiter Watch Program and with a special COSPAR working group to promote long-term coordinated studies of the Jovian environment using a wide variety of ground based and space-based instruments."

Dr. Brahic noted that it is too late to have a formal resolution passed by the IAU Executive Committee at this General Assembly, but following discussion, Commission 16 gave its informal endorsement of Dr. West's resolution.

6. Dr. B. A. Smith (USA) proposed that the scope of Commission 16 be broadened to encompass the study of protoplanetary disk phenornena (of the Beta Pictoris and related types), in a move that would be consistent with the new policy at the US National Aeronautics and Space Administration to include the study of these phenomena within the discipline of planetary science. Dr. Brahic noted that it is too late to make this a formal change at the current General Assembly, but urged that the members discussed Dr. Smith's proposal among themselves and with other astronomers, so that something formal can be undertaken at the next General Assembly.

When the meeting adjourned at about 11 : 00 a.m., approxirnately 30 people were in attendance.

Dale P. Cruikshank 